Check for updates

Cite this: RSC Adv., 2017, 7, 37158

Received 20th May 2017

Accepted 12th July 2017

DOI: 10.1039/c7ra05693a

rsc.li/rsc-advances

\title{
A sub-acute oral toxicity analysis and comparative in vivo anti-diabetic activity of zinc oxide, cerium oxide, silver nanoparticles, and Momordica charantia in streptozotocin-induced diabetic Wistar rats $\uparrow$
}

\author{
Kalakotla Shanker, (D) *a Jayarambabu Naradala, ${ }^{\text {b }}$ G. Krishna Mohan, ${ }^{a}$ G. S. Kumar ${ }^{\mathrm{c}}$ \\ and P. L. Pravallika ${ }^{a}$
}

Type 2 diabetes mellitus (T2DM) is one of the most threatening, non-communicable ailments worldwide. The use of nanoparticles as a medicine in the treatment of T2DM is an attractive proposition. In the current study, zinc oxide nanoparticles ( $\mathrm{n} \mathrm{nO} \mathrm{NPs})$, cerium oxide nanoparticles $\left(\mathrm{CeO}_{2} \mathrm{NPs}\right)$, silver nanoparticles (Ag NPs), and Momordica charantia (MC) were evaluated for their in vivo anti-diabetic activity. The resulting $\mathrm{ZnO}, \mathrm{CeO}_{2}$, and Ag NPs were characterized via various techniques such as XRD, FT-IR, PSA, and SEM. The synthesized NPs and MC extract were tested for toxicity using a sub-acute oral toxicity model by following the OECD 425 guidelines. The male Wistar rats with weights in the range of 180-200 g were grouped as follows: normal control: who did not receive any treatment; diabetic control: who received a single intraperitoneal dose of streptozotocin $\left(40 \mathrm{mg} \mathrm{kg}{ }^{-1}\right)$; standard: who received a single daily oral dose of streptozotocin $50 \mathrm{mg}$ per $\mathrm{kg}$ body weight; diabetic and $\mathrm{ZnO}$ NPs: who received a single daily oral dose of $100 \mathrm{mg} \mathrm{kg}^{-1}$ and $200 \mathrm{mg} \mathrm{kg}^{-1}$ of ZnO NPs; diabetic and $\mathrm{CeO}_{2} \mathrm{NPs}$ : who received a single daily oral dose of $100 \mathrm{mg} \mathrm{kg}^{-1}$ and $200 \mathrm{mg} \mathrm{kg}^{-1}$ of $\mathrm{CeO}_{2} \mathrm{NPs}_{\text {; }}$ diabetic and Ag NPs: who received a single daily oral dose of $100 \mathrm{mg} \mathrm{kg}^{-1}$ and $200 \mathrm{mg} \mathrm{kg}^{-1}$ of Ag NPs; and diabetic and MC: who received a single daily oral dose of $100 \mathrm{mg} \mathrm{kg}^{-1}$ and $200 \mathrm{mg} \mathrm{kg}^{-1}$ of MC. In conclusion, the green-synthesized NPs showed no toxic effect and were considered safe. From the experimental results, it may be concluded that due to the extensive biological and pharmacological properties, the ZnO NPs and Ag NPs had more potent anti-hyperglycemic activity than $\mathrm{MC}$ and $\mathrm{CeO}_{2} \mathrm{NPs}$. Further pharmacokinetic studies are required to establish the exact mechanism of action (of NPs).

\section{Introduction}

Type-2 Diabetes Mellitus (T2DM) has shown an alarming upswing globally and has been positioned as the fifth prominent origin of death in the world. This disease is related to deliberate complications including diabetic neuropathy, peripheral vascular disease, and diabetic neuropathy and renal failure. ${ }^{1,2}$

${ }^{a}$ Centre for Pharmaceutical Sciences, Institute of Science and Technology, Jawaharlal Nehru Technological University, Kukatpally, Hyderabad, Telangana, 500085, India. Fax: +91-040-23158666; Tel: +91-040-23158666. E-mail: kalakotlashanker@gmail. com

${ }^{b}$ Centre for Nanoscience and Technology, Institute of Science and Technology, Jawaharlal Nehru Technological University, Kukatpally, Hyderabad, Telangana, 500085, India

${ }^{c}$ Department of Life Sciences, School of Pharmacy, International Medical University, No. 126, Jalan Jalil Perkasa, Bukit Jalil, 57000 Kuala Lumpur, Malaysia

$\dagger$ Electronic supplementary information (ESI) available. See DOI: 10.1039/c7ra05693a
The present scenario of rapid worldwide increase in diabetes cases are associated with the rapid advances in the unhealthy lifestyle of human, urbanization, and aging; global assessment of diabetics for the past three decades has shown an increase in the cases from 153 million to 368 million. Currently, 382 million cases of diabetes have been estimated in 2016, and they are speculated to rise to 592 million by the year $2035 .^{3,4}$

Treatment of T2DM using medicinally active plants is in practice all over the world. Momordica charantia, also known as bitter gourd, balsam pear, melon, and karela, is a wellknown nutritious plant used for the treatment of diabetes amongst the indigenous people of Asia, South America, India, and the Caribbean. ${ }^{5-8}$ MC's fruit has a distinguishing bitter taste, which gets more pronounced as it ripens; therefore, it is called bitter melon or bitter gourd. Biochemical and animal model experiments have produced abundant data and hypotheses accounting for the anti-diabetic effects of the MC extract. In comparison, clinical studies with 
human subjects are sparse and low quality in design. An increasing number of patients opt for nanoherbal remedies driven by a combination of factors including higher bioavailability, lower dosage, and greater compliance. Many findings have depicted the key role of metals in glucose metabolism and the relationship of their inadequacy with diabetes. Silver, ${ }^{9-13}$ vanadium, chromium, magnesium, and zinc oxide have been reported to play a role in the reduction of glucose levels and included in diabetes therapy and possess many other pharmacological properties. The valuable role of zinc in the treatment of diabetes has been embroiled via investigations of zinc supplies in diabetic rats. ${ }^{\mathbf{1 4}, 15}$ Although $\mathrm{CeO}_{2}$ is an important metal in a huge number of metabolic processes, there are no data about the effectiveness of this metal in glucose reduction using animal models. Ag NPs have already been proven to possess antidiabetic activity in our previous study. ${ }^{16}$ From current research in the field of herbal nanomedicine, it is clearly shown that the green synthesized nanoparticles are effective than the crude extracts since the nanoparticles offer some advantages, such as higher surface area, high solubility, and enhanced therapeutic activity. This encouraged us to study the therapeutic effect of the MC extract in comparison with that of the $\mathrm{ZnO} \mathrm{NPs}, \mathrm{CeO}_{2} \mathrm{NPs}$, and $\mathrm{Ag}$ NPs.

\section{Experimental details}

\section{Materials}

Momordica charantia (MC) fruits were obtained from JNT University premises. Zinc nitrate (Sigma Aldrich), cerium nitrate (Sigma Aldrich), ethanol, and distilled water were used in the synthesis process in their pure form without any further modification.

\section{Plant extraction: Soxhlet extraction}

The MC fruits were washed to remove the adhering mud particles and possible impurities. Then, they were dried under sunlight for a week to completely remove the moisture. The fruits were cut into small pieces, powdered in a mixer, and then sieved using a 20 mesh sieve to obtain a uniform size range. The coarse powder was packed in a Soxhlet apparatus and allowed to undergo solvent extraction using water. The aqueous extract was concentrated using a rota evaporator, and then, the resultant product was stored in a desiccator until further use. ${ }^{17}$ The nature of the extract was as follows; state: semi solid; color: dark green; and solubility: soluble in water.

\section{Biological synthesis of $\mathrm{ZnO}, \mathrm{CeO}_{2}$, and $\mathrm{Ag} \mathrm{NPs}$}

The $\mathrm{ZnO}, \mathrm{CeO}_{2}$, and $\mathrm{Ag}$ NPs nanoparticles were synthesized using the simple green synthesis method. In this method, $\mathrm{ZnO}$

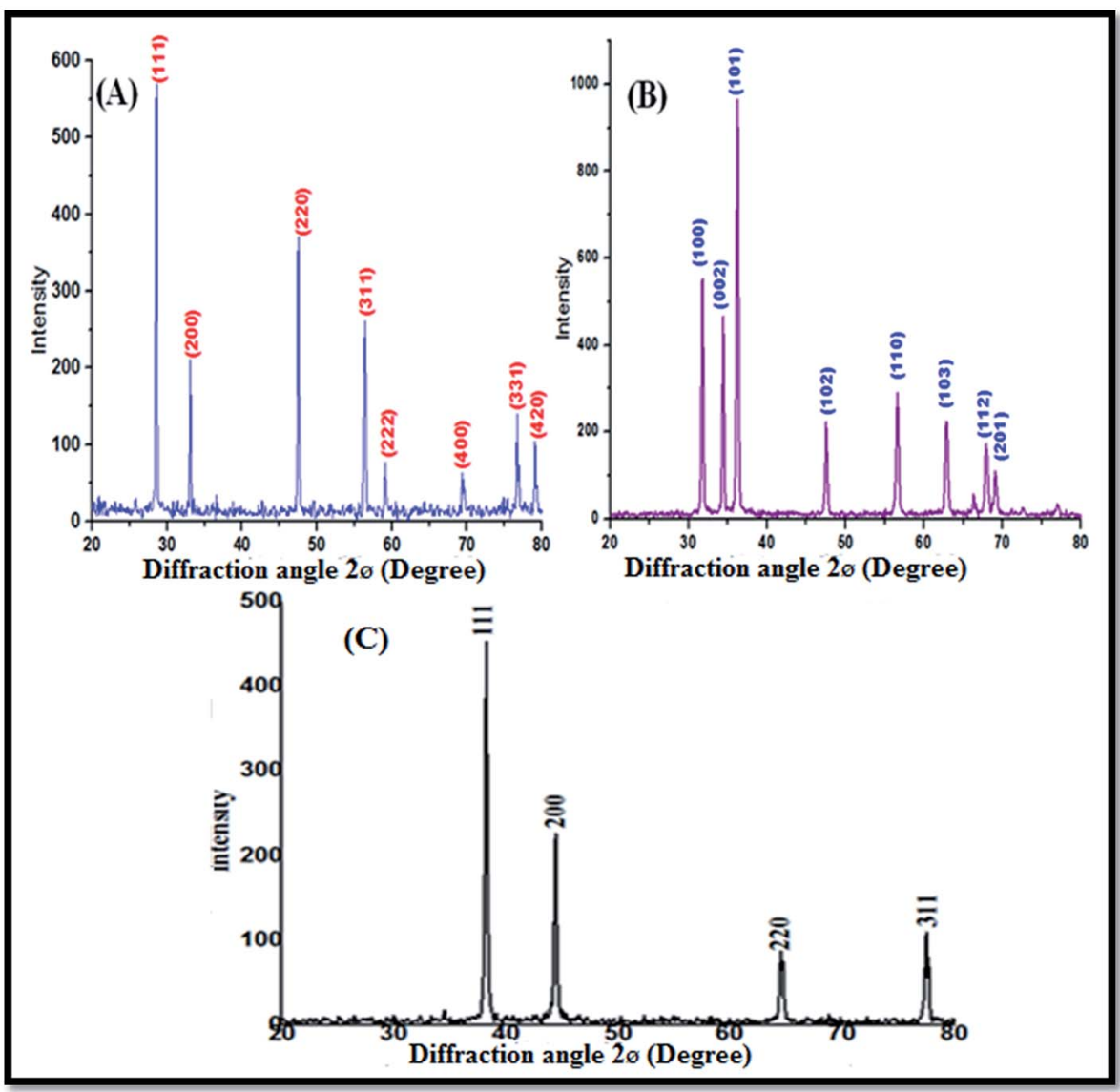

Fig. 1 XRD patterns of the (A) ZnO NPs, (B) $\mathrm{CeO}_{2} \mathrm{NPs}$, and (C) Ag NPs. 
and $\mathrm{CeO}_{2}$ were synthesized by adding distilled water to $0.5 \mathrm{mM}$ of precursor (zinc nitrate for $\mathrm{ZnO}$ and cerium nitrate for $\mathrm{CeO}_{2}$ ) under constant magnetic stirring. Then, $25 \mathrm{ml}$ of MC aqueous extract was added dropwise to the abovementioned solution, and this mixed solution was then placed on a magnetic stirrer for $2 \mathrm{~h}$ at $70{ }^{\circ} \mathrm{C}$. The resultant solution was placed in an autoclave for 5 cycles $(1$ cycle $=20$ minutes). After terminating the reaction, the semi liquid, light brown precipitate obtained was placed in a microwave until the solvent evaporated. The precipitate was taken out and thoroughly washed with distilled water followed by ethanol to get rid of the impurities; then, a powder of $\mathrm{ZnO}$ and $\mathrm{CeO}_{2}$ nanoparticles was obtained. The resulting $\mathrm{ZnO}$ and $\mathrm{CeO}_{2}$ powder was annealed at $400{ }^{\circ} \mathrm{C}$ for 4 h. ${ }^{18,19}$

The procedure of Ag NPs synthesis was well described in our previous study using a medicinally active plant extract. ${ }^{16}$ The Ag NPs were synthesized by adding $10 \mathrm{ml}$ of the filtered plant extract to the conical flasks containing $90 \mathrm{ml}$ of silver nitrate solution, and the mixed solution was vigorously stirring using a magnetic stirrer. The conical flasks were then incubated at room temperature for $24 \mathrm{~h}$. The solution changed from light green to dark brown; this indicated the formation of Ag NPs. The change in the color indicated the formation of Ag NPs. The dark brown-colored solution was centrifuged at 4000 RPM for 30 minutes.

\section{Characterization of the green-synthesized nanoparticles}

The nanoparticles were characterized by various methods such as X-ray diffraction, Fourier transform infrared spectroscopy, particle size analysis, and scanning electron microscopy to determine the crystalline nature, functional groups present, average particle size, and morphology of the $\mathrm{ZnO}, \mathrm{CeO}_{2}$, and $\mathrm{Ag}$ NPs, respectively.

\section{In vivo sub-acute oral toxicity study}

Female Swiss albino mice weighing between 20 and $30 \mathrm{~g}$ were used and bred in the Central Animal House facility of Pullareddy Institute of Pharmacy, Hyderabad (Reg. no. 1684/PO/a/ 13/CPCSEA). All the animals were maintained under standard laboratory conditions i.e. temperature of $20 \pm 2{ }^{\circ} \mathrm{C}$; relative humidity of 45-55\%; and a $12: 12$ hour light/dark cycle. The animals had free access to a standard pellet diet (Amrut feeds, Bangalore), with water provided ad libitum under strict hygienic conditions. The animals were divided into 10 groups of 6 animals each. The normal control received normal distilled water $\left(2 \mathrm{ml} \mathrm{kg}^{-1}\right.$, p.o.), and the other groups received a graded dose $\left(800,1000\right.$, and $2000 \mathrm{mg} \mathrm{kg}^{-1}$ ) of the $\mathrm{Zn} \mathrm{O} \mathrm{NPs,} \mathrm{CeO}_{2}$, and $\mathrm{Ag}$ NPs (3 doses of each test drug), respectively. Immediately after dosing, the animals were continuously observed for the first 4 hours for any behavioural changes and death, if any, intermittently for the next $6 \mathrm{~h}$, and then again at $24 \mathrm{~h}$ after dosing. They were then kept under observation up to 28 days after drug administration to find out the mortality, if any. ${ }^{\mathbf{2 0 , 2 1}}$ The observations were made twice daily: one at 8 a.m. and another at 8 p.m.

\section{Histopathology study}

On the 28th day of the sub-acute oral toxicity study, the selected group of mice was sacrificed with intraperitoneal administration of $30 \mathrm{mg}$ per $\mathrm{kg}$ phenobarbital, and organs such as the pancreas, kidney, spleen, heart, and liver were surgically detached to perform the histopathological studies. The isolated sections were examined carefully under a microscope using slides. The histopathological changeover deviations from the normal group were carefully obtained.

\section{Experimental animals, induction of diabetes, and insulin} assay

Male Wistar rats, weighing between 180 and $200 \mathrm{~g}$ (Fig. S1 $\dagger$ ), were procured from Mahaveer enterprises, Uppal, Hyderabad, Telangana, India. The protocol for conducting the animal study was approved by the Institutional Animal Ethical Committee (IAEC) through its reference number 1684/PO/a/13/CPCSEA. The selected animals were housed in acrylic cages (six per cage) at $25{ }^{\circ} \mathrm{C}, 45-55 \%$ humidity, and 12/12 h light/dark under controlled environment. The rats were fed with standard laboratory diet (Fig. S2 $\dagger$ ), and water was given ad libitum. Prior to the experiment, a freshly prepared solution of streptozotocin (40 $\mathrm{mg} \mathrm{kg}^{-1}$ in $0.1 \mathrm{M}$ citrate buffer, $\mathrm{pH} 4.5$ ) was intraperitoneally injected (Fig. S3†) into overnight fasted Wistar rats. The rats elicited hyperglycemia after 48 hours of STZ administration. The rats with the blood glucose levels of $250 \mathrm{mg} \mathrm{dl}^{-1}$ or above were chosen for the study (Fig. S5†).

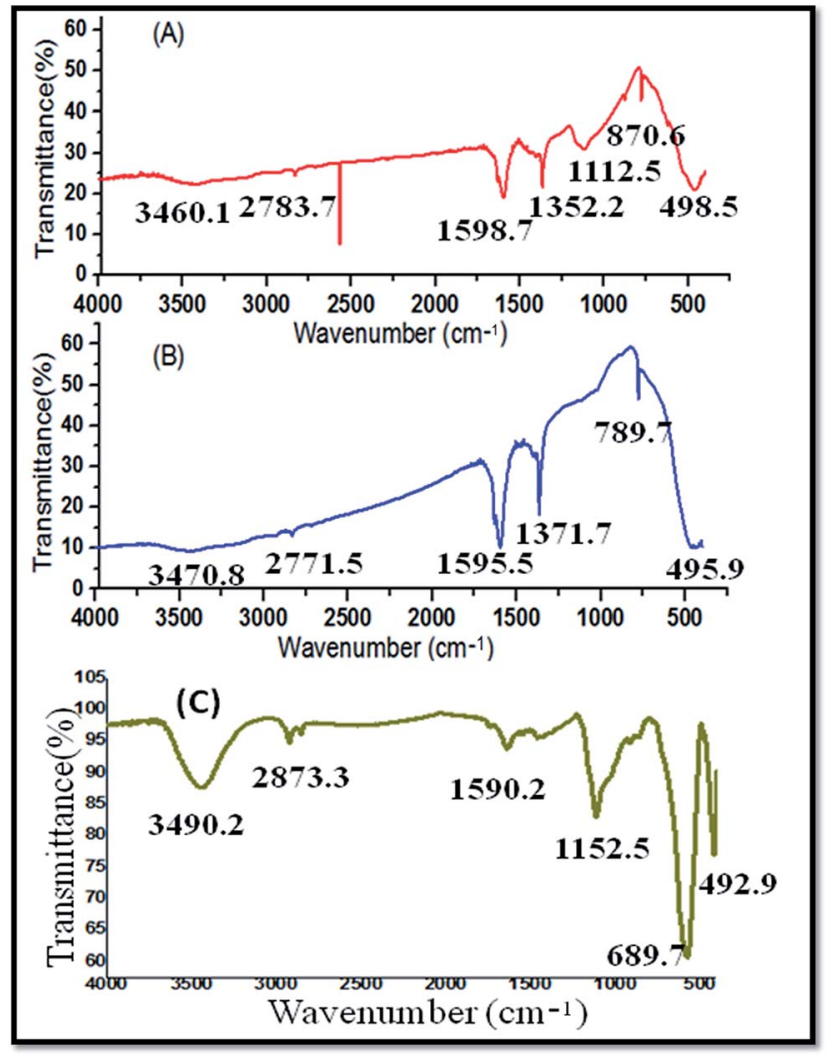

Fig. 2 FT-IR spectra of the (A) $\mathrm{CeO}_{2}$ NPs, (B) ZnO NPs, and (C) Ag NPs. 


\section{Hypoglycemic activity in non-diabetic fasted rats (OGTT) ${ }^{22}$}

The rats were fasted and divided into eight groups of six animals each. The group I animals received only vehicle $(0.9 \%$ $\mathrm{w} / \mathrm{v}$ saline) orally in a volume of $0.5 \mathrm{ml} \mathrm{kg}^{-1}$ and served as a control. Group II received metformin (50 $\mathrm{mg} \mathrm{kg}^{-1}$, p.o.) as a reference drug suspended in a vehicle (Fig. S8 $\dagger$ ). ZnO NPs (100 and $200 \mathrm{mg} \mathrm{kg}^{-1}$ ), $\mathrm{CeO}_{2}$ NPs (100 and $200 \mathrm{mg} \mathrm{kg}^{-1}$ ), and $\mathrm{Ag}$ NPs (100 and $200 \mathrm{mg} \mathrm{kg}^{-1}$ ) were administered (Fig. S4 $\dagger$ ) to the animals of groups III, IV, V, VI, VII, and VIII, respectively. Blood samples were obtained from the retro orbital sinus under ether inhalation at $0,30,60$, and $120 \mathrm{~min}$ for estimation of glucose level via Accu Chek.

\section{Anti hyperglycemic study design}

Group I - normal control rats received saline.

Group II - diabetic control received STZ (40 $\mathrm{mg} \mathrm{kg}^{-1}$, p.o.).

Group III - diabetic control treated with metformin (50 mg $\mathrm{kg}^{-1}$, p.o.).

Group IV - diabetic control treated with $\mathrm{CeO}_{2} \mathrm{NPs}(100 \mathrm{mg}$ $\mathrm{kg}^{-1}$ in, p.o.).

Group V - diabetic control treated with $\mathrm{CeO}_{2}$ NPs $(200 \mathrm{mg}$ $\mathrm{kg}^{-1}$ in, p.o.).
Group VI - diabetic control treated with ZnO NPs (100 mg $\mathrm{kg}^{-1}$, p.o.).

Group VII - diabetic control treated with ZnO NPs $(200 \mathrm{mg}$ $\mathrm{kg}^{-1}$, p.o.).

Group VIII - diabetic control treated with Ag NPs (100 mg $\mathrm{kg}^{-1}$, p.o.).

Group IX - diabetic control treated with Ag NPs (200 mg $\mathrm{kg}^{-1}$, p.o.).

Group $\mathrm{X}$ - diabetic control treated with MC $\left(100 \mathrm{mg} \mathrm{kg}{ }^{-1}\right.$, p.o.).

Group XI - diabetic control treated with MC $\left(200 \mathrm{mg} \mathrm{kg}{ }^{-1}\right.$, p.o.).

By the end of the experimental duration, blood was withdrawn by retro orbital puncture and centrifuged using a rapid centrifuge (REMI-CM12) at $5000 \mathrm{rpm}$. Serum glucose was estimated on the 14th day using a fully automatic biochemistry analyzer (SPHEARA-ACCUREX455). Simultaneously, the fasting serum insulin was estimated by following the method described by Andersen et al., 1993 (ref. 23) using a fully automatic enzyme linked immunoassay (ELISA). On the 15th day of the study, the animals were sacrificed and the important organs such as the pancreas, liver, etc., were removed and subjected to histopathological studies.

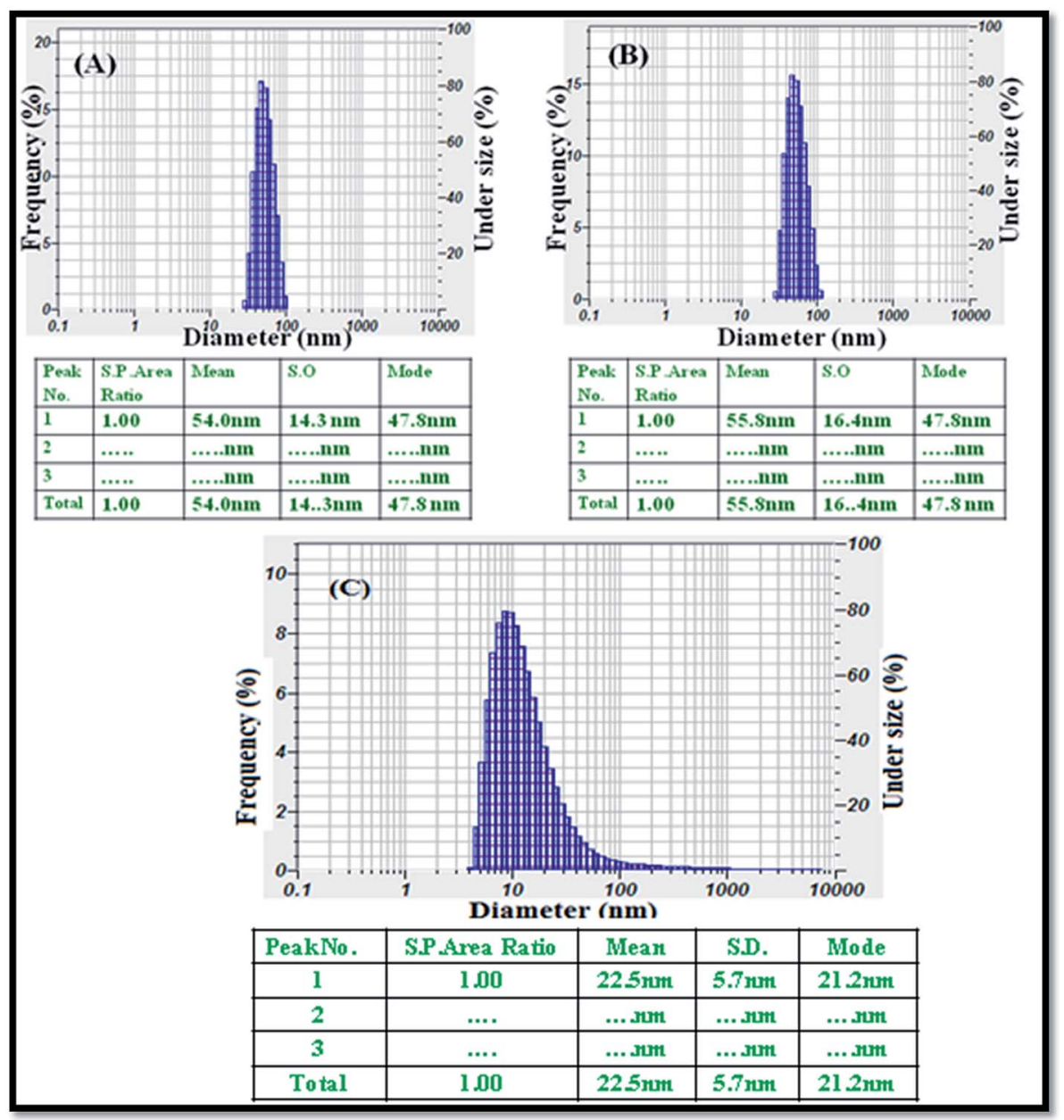

Fig. 3 DLS graphs of the (A) $\mathrm{CeO}_{2}$ NPs, (B) ZnO NPs, and (C) Ag NPs. 


\section{Statistical analysis}

The results were expressed as mean \pm S.E.M. For statistical analysis of the data group, the mean was compared using a oneway analysis of variance (ANOVA) followed by the Dunnett's test. $p<0.001$ was considered to be statistically significant.

\section{Results and discussion}

Fig. 1A shows the XRD profile of the green-synthesized $\mathrm{CeO}_{2} \mathrm{NPs}$, which possess single-phase cubic fluorite structure without any additional peaks. The several broad Bragg peaks correspond to (111), (200), (220), (311), (222), (400), (331), and (420) orientations, and they are precisely well indexed to the Joint Committee on Powder Diffraction Standards (JCPDS card no. 34-0394). This later crystallographic phase indicates that each cerium site is encountered by eight oxygen sites in the face-centered cubic arrangement, whereas each oxygen has the geometry of the tetrahedron cerium site. Using the Debye-Scherrer approximation and from the broadening of the peaks, the approximate crystallite size of the $\mathrm{CeO}_{2}$ NPs was found to be $24 \mathrm{~nm}$.

Fig. 1B depicts the diffraction peaks at $2 \theta$ corresponding to $31.8,34.4,36.2,47.6,56.3,66.2,67.8,69.1,72.5$, and $76.7^{\circ}$ attributed to the crystal planes of ZnO NPs (100), (002), (102), (110), (103), (200), (112), (201), (004), and (202), respectively, with the characteristics of the hexagonal wurtzite structure, JCPDS card no. 36-1451. No other diffraction peaks were detected in the XRD spectrum of the ZnO NPs; this indicated that the precursor material completely decomposed and no other crystalline impurity peaks were found. The average crystalline size of the ZnO NPs can be calculated from the Debye-Scherrer's formula $D=0.9(B \cos q)$. The average crystalline size of the ZnO NPs was found to be about $25 \mathrm{~nm}$.

Fig. 1C shows the XRD characteristic peaks of the Ag NPs at $2 \theta=38.23^{\circ}, 44.33^{\circ}, 64.56^{\circ}$, and $77.45^{\circ}$, which correspond to (111), (200), (220), and (311), respectively (JCPDS no. 89-3799).

The FT-IR spectrum of the $\mathrm{CeO}_{2}$ NPs (Fig. 2A) was obtained in the wave number range of $450-4000 \mathrm{~cm}^{-1}$. The bonds at $2700-1600 \mathrm{~cm}^{-1}$ represent the water and the hydroxyl stretches, respectively. The intensive peak at $1371.7 \mathrm{~cm}^{-1}$ represents alcohol and ester $(\mathrm{C}-\mathrm{O})$ functionalities, which may originate due to the compounds present in the MC plant extract that was used for the green synthesis of $\mathrm{CeO}_{2} \mathrm{NPs}$. The strong stretching band at 700-490 $\mathrm{cm}^{-1}$ represents the $\mathrm{CeO}_{2} \mathrm{NPs}$.

FT-IR spectral analysis of pure white $\mathrm{ZnO}$ powder was carried out after calcination at $200{ }^{\circ} \mathrm{C}$ for 2 hours. Fig. 2B exhibits strong absorption bands around 870.6-498.5 $\mathrm{cm}^{-1}$, confirming the $\mathrm{Zn}-\mathrm{O}$ stretching frequencies. The peak at $1112.5 \mathrm{~cm}^{-1}$ represents alcohols and esters $(\mathrm{C}-\mathrm{O})$. Furthermore, the peaks around $1600-1400 \mathrm{~cm}^{-1}$ represent $\mathrm{N}-\mathrm{H}$ (bending) and $\mathrm{N}-\mathrm{H}$ (stretching), which are associated with molecules containing amines and amides. The peak between 3460.1 and $2783.7 \mathrm{~cm}^{-1}$ belongs to alcohols $(-\mathrm{OH})$. In the green synthesis of ZnO NPs, the Momordica charantia aqueous extract was used for the synthesis of the nanoparticles. Hence, in this method, chemical agents, surfactant, etc., were not used for the synthesis of the nanoparticles.

The functional groups present in the Ag NPs were identified by the FT-IR analysis. The Ag NPs contained functional groups

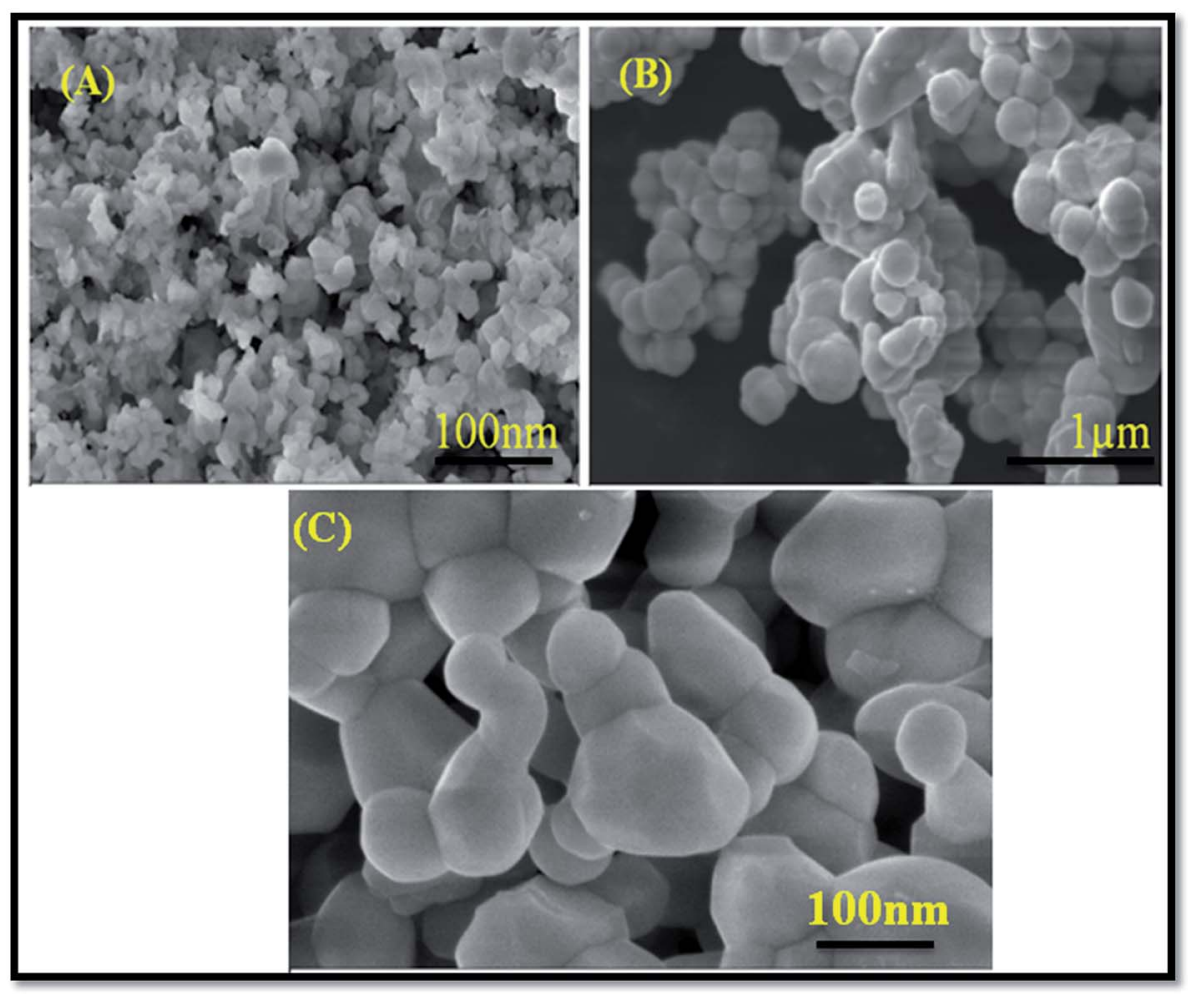

Fig. 4 SEM images of the (A) $\mathrm{CeO}_{2}$ NPs, (B) ZnO NPs, and (C) Ag NPs. 
such as alcohols $(-\mathrm{OH})$ at $3490.2 \mathrm{~cm}^{-1}$, esters $(\mathrm{C}-\mathrm{O})$ at 1152.2 $\mathrm{cm}^{-1}$, and amines and amides $(\mathrm{N}-\mathrm{H})$ at $1590.2 \mathrm{~cm}^{-1}$ (Fig. 2C).

The average particle size was analysed using a particle size analyser, and the size distribution of the $\mathrm{CeO}_{2}$ (Fig. 3A), $\mathrm{ZnO}$ NPs (Fig. 3B), and Ag NPs (Fig. 3C) produced by the green method was observed. The nanomaterials were completely dispersed in the ethanol solution using an ultrasonicator for 30 minutes. The histograms of the PSA indicate that the average sizes of the obtained nanoparticles i.e., $\mathrm{CeO}_{2}, \mathrm{ZnO}$ NPs, and $\mathrm{Ag}$ NPs were 54, 55.8, and $22.5 \mathrm{~nm}$, respectively.

Fig. 4A depicts the SEM images of the green-synthesized $\mathrm{CeO}_{2}$ NPs. It is obvious from the SEM image that the $\mathrm{CeO}_{2}$
NPs were highly homogeneous and symmetrical in morphology with a spherical shape. Similarly, the ZnO NPs (Fig. 4B) were homogenous and symmetrical in the morphological shape with a uniform average grain size of less than $100 \mathrm{~mm}$. The greensynthesized Ag NPs were well distributed without any aggregation and acquired a spherical shape (Fig. 4C).

Isolated tissues, including pancreas, kidney, spleen, heart, and liver, of female mice were investigated after exposure to $\mathrm{ZnO} \mathrm{NPs}, \mathrm{CeO}_{2}$, and $\mathrm{Ag}$ NPs and compared with those of the control group. ${ }^{24}$ After dissection, the individual organs were weighed and no significant differences between the body weights of animals and (Table 4 ) organ weights of the control

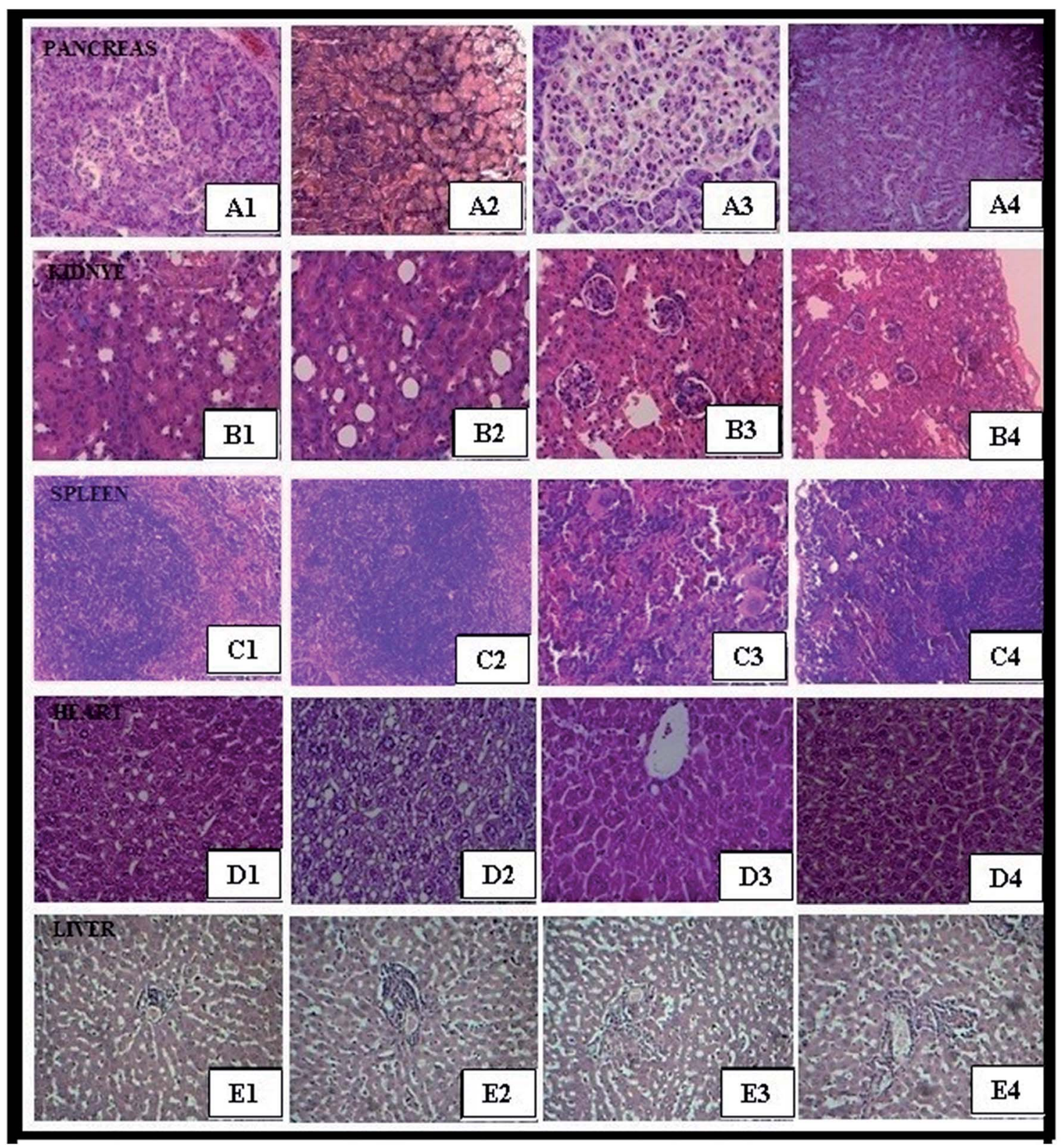

Fig. 5 Histopathology of female mice pancreas, kidney, spleen, heart and liver for normal control group (A1, B1, C1, D1, and E1); histopathology of pancreas, kidney, spleen, heart and liver for ZnO NPs treated group (A2, B2, C2, D2, and E2); histopathology of pancreas, kidney, spleen, heart and liver for $\mathrm{CeO}_{2}$ NPs treated group (A3, B3, C3, D3, and E3); histopathology of pancreas, kidney, spleen, heart and liver for Ag NPs treated group (A4, B4, C4, D4, and E4). 
Table 1 Effect of $\mathrm{CeO}_{2}, \mathrm{ZnO}, \mathrm{Ag}$ NPs and MC on fasted normal Wistar rats ${ }^{a}$

\begin{tabular}{|c|c|c|c|c|c|}
\hline Treatment and dose & $0 \mathrm{~min}$ & $30 \mathrm{~min}$ & $60 \mathrm{~min}$ & $90 \mathrm{~min}$ & $120 \mathrm{~min}$ \\
\hline Normal control & $93.40 \pm 1.18$ & $98.83 \pm 1.23$ & $95.56 \pm 1.24$ & $91.97 \pm 1.17$ & $90.87 \pm 1.29$ \\
\hline Metformin $\left(40 \mathrm{mg} \mathrm{kg}^{-1}\right)$ & $90.38 \pm 1.86$ & $84.57 \pm 1.45$ & $79.73 \pm 1.65^{b}$ & $67.69 \pm 1.08^{b}$ & $51.08 \pm 1.76^{b}$ \\
\hline ZnO NPs $\left(200 \mathrm{mg} \mathrm{kg}^{-1}\right)$ & $89.42 \pm 1.93$ & $91.72 \pm 1.65$ & $93.28 \pm 1.65$ & $93.90 \pm 1.09$ & $88.43 \pm 1.09$ \\
\hline $\mathrm{CeO}_{2}$ NPs $\left(100 \mathrm{mg} \mathrm{kg}^{-1}\right)$ & $88.65 \pm 1.76$ & $90.82 \pm 1.14$ & $94.28 \pm 1.77$ & $93.87 \pm 1.21$ & $89.98 \pm 1.94$ \\
\hline $\mathrm{CeO}_{2}$ NPs $\left(200 \mathrm{mg} \mathrm{kg}^{-1}\right)$ & $91.98 \pm 1.62$ & $92.2 .3 \pm 1.02$ & $91.15 \pm 1.50$ & $85.78 \pm 1.43$ & $87.21 \pm 1.82$ \\
\hline MC $\left(100 \mathrm{mg} \mathrm{kg}^{-1}\right)$ & $92.09 \pm 0.20$ & $90.88 \pm 1.09$ & $91.10 \pm 1.04$ & $93.78 \pm 1.32$ & $94.05 \pm 0.79^{b}$ \\
\hline $\mathrm{MC}\left(200 \mathrm{mg} \mathrm{kg}{ }^{-1}\right)$ & $93.05 \pm 0.18$ & $90.03 \pm 1.30$ & $92.17 \pm 0.31$ & $90.64 \pm 0.16$ & $93.98 \pm 0.98^{b}$ \\
\hline
\end{tabular}

${ }^{a}$ The data are expressed as mean \pm S.E.M.; $n=6$ in each group. ${ }^{b} p<0.001$, significant when compared to normal control.

Table 2 Effect of $\mathrm{CeO}_{2}, \mathrm{ZnO}$ and Ag NPs on blood glucose levels in STZ induced diabetic rats ${ }^{a}$

\begin{tabular}{|c|c|c|c|c|c|}
\hline Normal control & $90.40 \pm 5.80$ & $94.83 \pm 3.01$ & $98.05 \pm 3.10$ & $91.97 \pm 1.45$ & $104.19 \pm 1.86$ \\
\hline Diabetic control (40 mg) & $280.65 \pm 5.05^{b}$ & $267.33 \pm 4.01^{b}$ & $275.89 \pm 3.95^{b}$ & $269.46 \pm 3.13^{b}$ & $268.89 \pm 3.76^{b}$ \\
\hline ZnO NPs (100 mg) & $282.13 \pm 4.21$ & $245.56 \pm 3.10$ & $236.27 \pm 1.92$ & $225.55 \pm 2.90$ & $160.32 \pm 2.99^{b}$ \\
\hline ZnO NPs (200 mg) & $279.98 \pm 11.00$ & $205.55 \pm 5.75$ & $160.22 \pm 2.34^{b}$ & $148.44 \pm 6.14^{b}$ & $132.07 \pm 6.21^{b}$ \\
\hline $\mathrm{CeO}_{2}$ NPs (100 mg) & $285.08 \pm 4.08$ & $260.08 \pm 2.01$ & $242.08 \pm 3.99$ & $246.05 \pm 3.27$ & $218.55 \pm 4.70$ \\
\hline Ag NPs (200 mg) & $280.98 \pm 10.00$ & $205.55 \pm 5.75$ & $150.22 \pm 2.40$ & $128.44 \pm 6.14^{b}$ & $103.07 \pm 6.21^{b}$ \\
\hline MC (100 mg) & $281.06 \pm 5.05^{b}$ & $261.05 \pm 2.04^{b}$ & $249.07 \pm 2.90^{b}$ & $240.21 \pm 2.03^{b}$ & $228.04 \pm 1.10^{b}$ \\
\hline MC (200 mg) & $284.55 \pm 2.13^{b}$ & $250.40 \pm 1.30^{b}$ & $240.65 \pm 1.06^{b}$ & $231.40 \pm 1.04^{b}$ & $214.98 \pm 3.43^{b}$ \\
\hline
\end{tabular}

${ }^{a}$ The data are expressed as mean \pm S.E.M.; $n=6$ in each group. ${ }^{b} p<0.001$, significant when compared to diabetic control.

and treated groups were observed (Table 5). Histopathology was performed to determine the effect of nanoparticles on the isolated organs. It was found that the histological sections (pancreas, kidney, spleen, heart, and liver) of the treated groups were similar to those of the control group (Fig. 5). The results distinctly indicate that the $\mathrm{ZnO} \mathrm{NPs}, \mathrm{CeO}_{2}$, and $\mathrm{Ag}$ NPs were coated with non-toxic plant extract, thus demonstrating the safe and therapeutic applications of these green-synthesized nanoparticles. As per the OECD guideline number 425, in vivo subacute oral toxicity studies of the green-synthesized ZnO NPs,
$\mathrm{CeO}_{2}$, and $\mathrm{Ag}$ NPs at three different dose levels were carried out. Further, it was found that oral administration of the greensynthesized nanoparticles did not bring about changes in the organ weight, abnormal growth, inflammation, and structural changes in organs; this indicated the biocompatible and nontoxic nature of the nanoparticles. There were no histopathological abnormalities noted.

In view of the oral glucose tolerance test (OGTT), $\mathrm{ZnO}, \mathrm{CeO}_{2}$, and Ag NPs were subjected to hypoglycemic activity testing at two dose levels (100 and $200 \mathrm{mg} \mathrm{kg}^{-1}$, respectively) as shown in

Table 3 Effect of $\mathrm{CeO}_{2}, \mathrm{ZnO}$ and $\mathrm{Ag}$ NPs on serum insulin level in diabetic rats ${ }^{a}$

\begin{tabular}{|c|c|c|}
\hline Group & Treatment and dose & Insulin levels $\left(\mu \mathrm{U} \mathrm{ml}{ }^{-1}\right)$ \\
\hline $\mathrm{I}$ & Normal control & $9.23 \pm 0.53$ \\
\hline II & Diabetic control (STZ $\left.40 \mathrm{mg} \mathrm{kg}^{-1}\right)$ & $3.62 \pm 0.83^{b}$ \\
\hline III & Diabetic control + metformin $\left(50 \mathrm{mg} \mathrm{kg}^{-1}\right)$ & $10.54 \pm 0.83^{b}$ \\
\hline IV & Diabetic control + ZnO NPs (100 mg kg $\left.\mathrm{kg}^{-1}\right)$ & $5.88 \pm 0.47$ \\
\hline $\mathrm{V}$ & Diabetic control + ZnO NPs $\left(200 \mathrm{mg} \mathrm{kg}^{-1}\right)$ & $6.98 \pm \mathbf{0 . 8 2} 2^{b}$ \\
\hline VI & Diabetic control $+\mathrm{CeO}_{2} \mathrm{NPs}\left(100 \mathrm{mg} \mathrm{kg}^{-1}\right)$ & $4.31 \pm 0.48$ \\
\hline VII & Diabetic control $+\mathrm{CeO}_{2}$ NPs $\left(200 \mathrm{mg} \mathrm{kg}^{-1}\right)$ & $5.66 \pm 0.67$ \\
\hline VIII & Diabetic control + Ag NPs $\left(100 \mathrm{mg} \mathrm{kg}^{-1}\right)$ & $6.87 \pm 0.67^{b}$ \\
\hline IX & Diabetic control + Ag NPs $\left(200 \mathrm{mg} \mathrm{kg}^{-1}\right)$ & $9.89 \pm 0.67^{b}$ \\
\hline $\mathrm{X}$ & Diabetic control + MC $\left(100 \mathrm{mg} \mathrm{kg}^{-1}\right)$ & $4.01 \pm 0.52$ \\
\hline XI & Diabetic control + MC $\left(200 \mathrm{mg} \mathrm{kg}^{-1}\right)$ & $4.43 \pm 0.61$ \\
\hline
\end{tabular}

${ }^{a}$ The data are expressed as mean \pm S.E.M.; $n=6$ in each group. ${ }^{b} p<0.001$, significant when compared to diabetic control. 
Table 1. From the results of the OGTT study, it was confirmed that the $\mathrm{ZnO}$ NPs, $\mathrm{CeO}_{2}$ NPs, and $\mathrm{Ag}$ NPs did not show any hypoglycemic activity in the untreated normal rats.

Table 2 demonstrates the effect of $\mathrm{ZnO}, \mathrm{CeO}_{2} \mathrm{NPs}$, and $\mathrm{Ag}$ NPs on the glucose levels of normal and STZ-induced diabetic rats. The control group rats (normal control group) exhibited normal blood glucose levels, whereas the STZ-induced diabetic rats (diabetic control group) showed considerably greater levels than those of the normal control rats. ${ }^{25}$ The occurrence of the hyperglycemic condition has resulted in uncontrolled glucose control brought on by the change in cellular metabolism in diabetic rats. ${ }^{26}$ Note that diabetic rats treated with Ag NPs and ZnO NPs altogether $(p<0.001)$ brought the biochemical parameters to the normal level, demonstrating the beneficial outcome of Ag NPs as well as ZnO NPs. The blood glucose levels were decreased at a dose range of $200 \mathrm{mg} \mathrm{kg}^{-1}$ of $\mathrm{ZnO}$ and $\mathrm{Ag}$ NPs, whereas the $\mathrm{CeO}_{2}$ NPs showed less anti-diabetic activity in the STZ-induced diabetic rats. Oral administration of the $\mathrm{ZnO}$ NPs and Ag NPs for a period of 14 days produced a significant reduction in the blood glucose levels as compared to that of the MC extract.

Fasting insulin levels in the Ag NP- and ZnO NP-treated diabetic rats restored the levels significantly $(p<0.001)$ to normalcy as compared to the diabetic control group and $\mathrm{CeO}_{2}$ NP- and MC-treated group rats (Table 3). The promising mechanism by which the NPs showed antidiabetic effects could be via potentiation of the pancreatic secretion of insulin from the existing $\beta$-cells of the islets, ${ }^{27}$ as was apparent via the critical increment in the level of insulin in the Ag NP- and ZnO NPtreated animal groups.

Fig. 6 demonstrates an islet of Langerhans of Wistar rats in the normal control group (I). The islet shows an extensive number of $\beta$ cells disseminated all through the islet. The islet of Langerhans demonstrated that the $\beta$ cells did not differ in

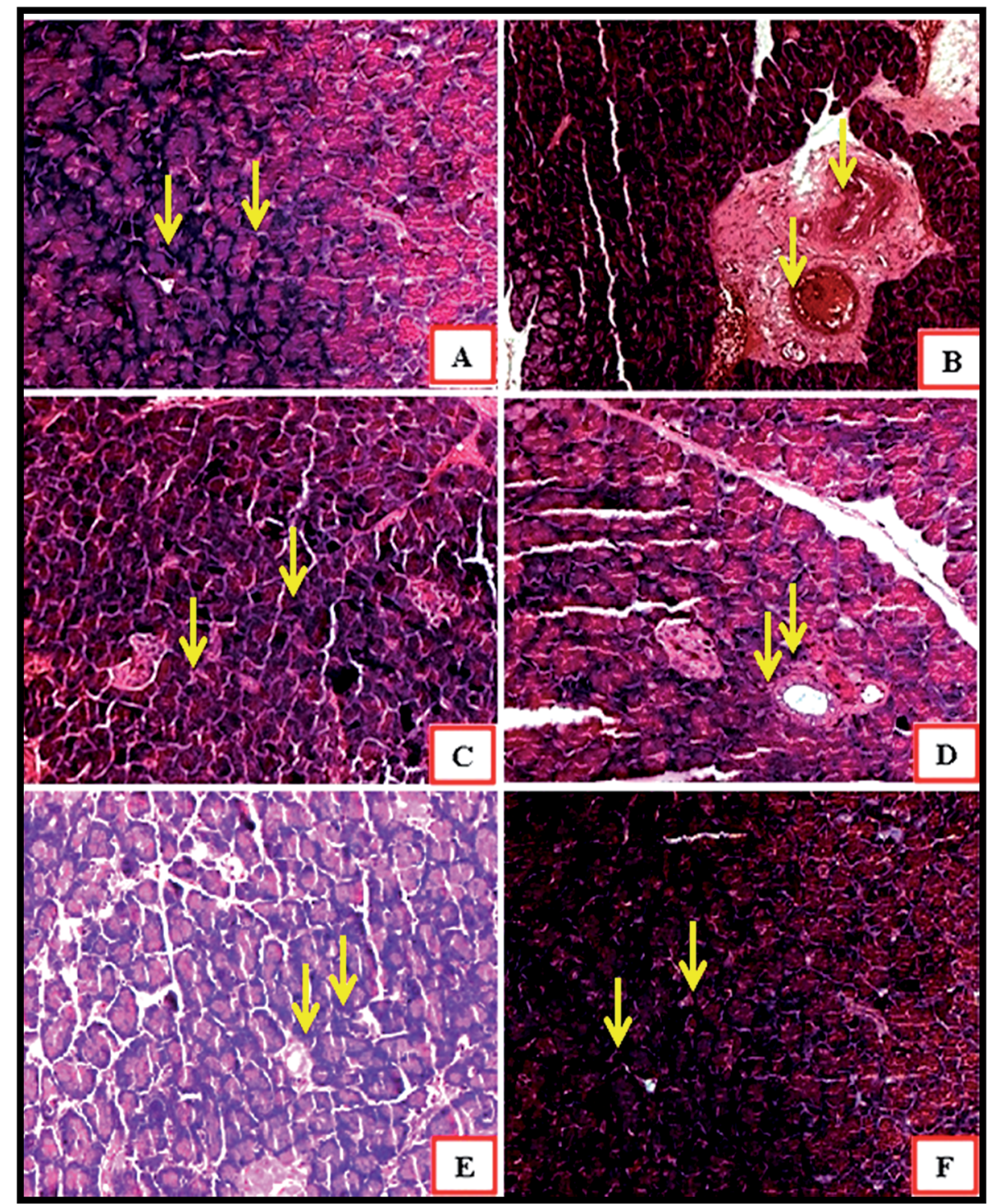

Fig. 6 (A) Histopathology of Wistar rats in normal control group, (B) diabetic control group, (C) DC + metformin standard treated group, (D) CeO 2 NPs treated group, (E) DC + ZnO NPs treated group, (F) DC + Ag NPs treated group. 
Table 4 Effect of $\mathrm{CeO}_{2}, \mathrm{ZnO}$ and Ag NPs on mice weight and signs of toxicity ${ }^{a}$

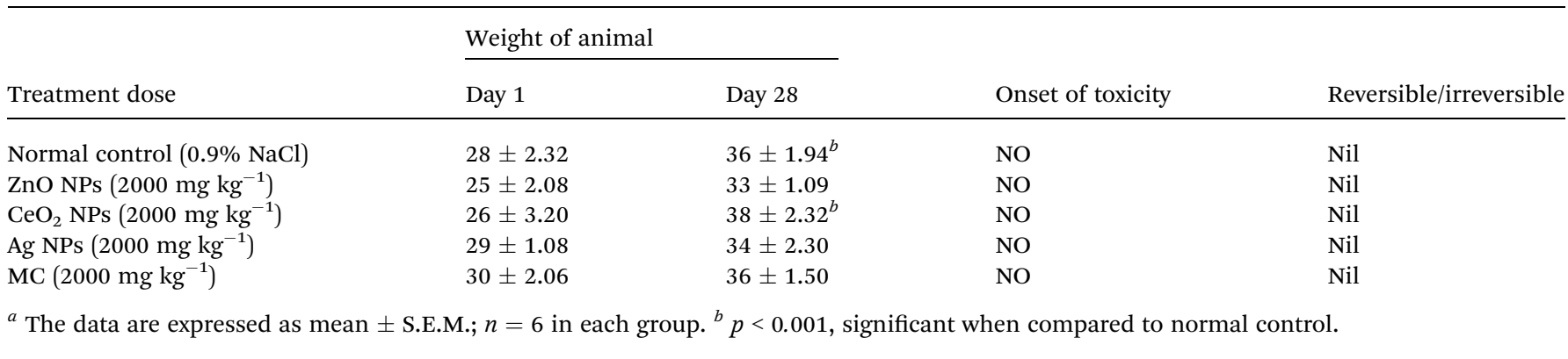

Table 5 Effect of $\mathrm{CeO}_{2}, \mathrm{ZnO}$ and $\mathrm{Ag} \mathrm{NPs}$ on weight of vital organs ${ }^{a}$

\begin{tabular}{|c|c|c|c|c|c|}
\hline Treatment dose & Pancreas & Kidney & Spleen & Heart & Liver \\
\hline ZnO NPs $\left(2000 \mathrm{mg} \mathrm{kg}^{-1}\right)$ & $1.25 \pm 0.41$ & $1.04 \pm 0.09$ & $1.40 \pm 0.28$ & $1.21 \pm 0.70$ & $7.02 \pm 0.90$ \\
\hline $\mathrm{CeO}_{2} \mathrm{NPs}\left(2000 \mathrm{mg} \mathrm{kg}^{-1}\right)$ & $1.18 \pm 0.70$ & $1.17 \pm 0.88$ & $1.21 \pm 0.39$ & $1.49 \pm 0.80^{b}$ & $7.99 \pm 1.40^{b}$ \\
\hline $\mathrm{Ag}$ NPs $\left(2000 \mathrm{mg} \mathrm{kg}^{-1}\right)$ & $1.40 \pm 0.52^{b}$ & $1.55 \pm 0.66^{b}$ & $1.26 \pm 0.30^{b}$ & $1.10 \pm 0.92$ & $6.82 \pm 0.23^{b}$ \\
\hline
\end{tabular}

${ }^{a}$ The data are expressed as mean \pm S.E.M.; $n=6$ in each group. ${ }^{b} p<0.001$, significant when compared to normal control.

group VII and VIII, neither in number nor in the distance across, from those of the normal control group.

In the diabetic control group, a decline in the quantity of $\beta$ cells was seen as compared to that in the normal control group rats (Fig. 6A and $\mathrm{B}$ ). The harm or putrefaction of the $\beta$ cells was brought about by the streptozotocin used to prompt diabetes.

Fig. 6C depicts the metformin-treated group animals; the $\beta$ cells present in this group seemed to be the same as those of the normal control group. Histopathology of the $\mathrm{CeO}_{2} \mathrm{NP}-$ and ZnO NP- (Fig. 6D and E) treated animal groups shows the partial regeneration of islets of Langerhans indicated by the yellow arrow marks. The damaged $\beta$ cells seen after the initial induction of diabetes were no longer observed after treatment with Ag NPs. The recovery of necrotic $\beta$ cells was especially more pronounced after treatment with $200 \mathrm{mg} \mathrm{kg}^{-1}$ of Ag NPs as compared to that in the group treated with $200 \mathrm{mg} \mathrm{kg}^{-1}$ of the $\mathrm{CeO}_{2}$ NPs and ZnO NPs. ${ }^{28-30}$

\section{Conclusion}

In the present study, we evaluated the toxic effects of the greensynthesized $\mathrm{ZnO}$ NPs, $\mathrm{CeO}_{2} \mathrm{NPs}$, and $\mathrm{Ag}$ NPs. Upon repeated administration, the NPs did not produce any mortality or indication of toxicity, as evaluated by the behaviour of albino mice and the histopathological microscopic examination of the isolated organs. As per the current study results, the administered green-synthesized ZnO NPs and Ag NPs showed potent anti-hyperglycemic properties as compared to the MC extract $\mathrm{CeO}_{2}$ NPs and likewise improved different entanglements of diabetes. Current global excitement in the use of eco-friendly and cost-effective resources drives the application of highly hailed medicinal plants to direct the green synthesis of nanoparticles that acquire diverse pharmacological properties. Accordingly, the $\mathrm{CeO}_{2}, \mathrm{ZnO}$, and $\mathrm{Ag}$ NPs were synthesized and characterized using XRD, FT-IR, PSA, and SEM. In addition, the hypothesis of the synthesis of these nanoparticles was to associate green synthesis (enhanced biological properties) with a natural plant (non-toxic and chemically inert) and to increase the surface area of the drug to achieve greater and potent therapeutic efficacy. Hence, comparatively, it is recommended that the Ag NPs and ZnO NPs are more potent than the plain extract, $\mathrm{CeO}_{2}$ NPs, and may be utilized as compelling nanomedicines that may be perfect alternatives to the crude extract for treatment of diabetes mellitus. However, further pharmacokinetic studies need to be explored.

\section{Acknowledgements}

This work has been financially supported by the Science and Engineering Research Board (SERB), New Delhi, India (Project Order No. SB/EMEQ-045/2013).

\section{References}

1 International Diabetes Federation, IDF diabetes atlas, International Diabetes Federation, Brussels, 2013, http:// www.Idf.org/diabetes atlas.

2 American Diabetes Association, American Diabetes Association, Diagnosis and classification of diabetes mellitus, Diabetes Care, 2011, 34, 62-69.

$3 \mathrm{~F}$. B. Hu, Globalization of diabetes: the role of diet, lifestyle, and genes, Diabetes Care, 2011, 34, 1249-1257. 
4 WHO, WHO traditional medicine strategy, 2014-2023, WHO, Geneva, 2013, http:/www.who.int/medicines/publications/ traditional/trm_strategy14_23/en/.

5 N. M. Balde, A. Youla, M. D. Balde, A. Kake and N. Diallo, Herbal medicine and treatment of diabetes in Africa: an example from Guinea, Diabetes Metab., 2006, 32, 171-175.

6 Z. M. Dastjerdi, F. Namjoyan and Md. E. Azemi, Alpha Amylase Inhibition Activity of Some Plants Extract of Teucrium Species, Eur. J. Biol. Sci., 2015, 7(1), 26-31.

7 Z. Q. Wang and W. T. Cefalu, Current concepts about chromium supplementation in type 2 diabetes and insulin resistance, Curr. Diabetes Rep., 2010, 10, 145-151.

8 B. Joseph and D. Jini, Antidiabetic effects of Momordica charantia (bitter melon) and its medicinal potency, Asian Pac. J. Trop. Dis., 2013, 3(2), 93-102.

9 K. Balan, W. Qing, Y. Wang, X. Liu, T. Palvannan, Y. Wang, F. Maa and Y. Zhanga, Antidiabetic activity of silver nanoparticles from green synthesis using Lonicera japonica leaf extract, $R S C$ Adv., 2016, 6, 40162-40168.

10 V. Karthick, V. Ganesh Kumar, T. Stalin Dhas, G. Singaravelu, A. Mohamed Sadiq and K. Govindaraju, Effect of biologically synthesized gold nanoparticles onalloxan-induced diabetic rats - an in vivo approach, Colloids Surf., B, 2014, 122, 505-511.

11 T. Stalin Dhas, V. Ganesh Kumar, V. Karthick, K. Vasanth, G. Singaravelu and K. Govindaraju, Effect of biosynthesized gold nanoparticles by Sargassum swartzii inalloxan induced diabetic rats, Enzyme Microb. Technol, 2016, 95, 100-106.

12 I. Mulyani, A. Levina and P. A. Lay, Biomimetic oxidation of chromium(III): does the antidiabetic activity of chromium(III) involve carcinogenic chromium(vi), Angew. Chem., Int. Ed., 2004, 43, 4504-4507.

13 R. D. Umrani and K. M. Paknikar, Zinc oxide nanoparticles show antidiabetic activity in streptozotocin-induced type 1 and 2 diabetic rats, Nanomedicine, 2014, 9, 89-104.

14 K. H. Thompson, J. Lichter, M. LeBel, M. C. Scaife, J. H. McNeill and C. Orvig, Vanadium treatment of type 2 diabetes: a view to the future, J. Inorg. Biochem., 2009, 103, 554-558.

15 I. C. Wells, Evidence that the etiology of the syndrome containing type 2 diabetes mellitus results from abnormal magnesium metabolism, Can. J. Physiol. Pharmacol., 2008, 86, 16-24.

16 K. Shanker, G. Krishna Mohan and V. Mayasa, Antihyperglycemic and anti-hyperlipidemic effect of biologically synthesized silver nanoparticles and G. sylvestre extract on streptozotocin induced diabetic rats-an in vivo approach, Mater. Lett., 2017, 195, 240-244.
17 R. Murugan and T. Parimelazhagan, Comparative evaluation of different extraction methods for antioxidant and antiinflammatory properties from Osbeckia parvifolia - an in vitro approach, J. King Saud Univ., Sci., 2014, 26(4), 267-275.

$18 \mathrm{H}$. Mirzaei and M. Darroudi, Zinc oxide nanoparticles: Biological synthesis and biomedical applications, Ceram. Int., 2017, 43(1), 907-914.

19 S. Jafarirad, M. Mehrabi and E. Rassul pur, Biological Synthesis of Zinc Oxide and Copper Oxide Nanoparticles International Conference on Chemistry, Biomedical and Environment Engineering (ICCBEE'14), Antalya, Turkey, Oct 7-8, 2014.

20 T. Ghosh, T. K. Maity, M. Das, A. Bose and G. K. Dash, Hepatoprotective activity of Bacopa monnieri L. against ethanol induced hepatotoxic rats, Pharmacogn. Mag., 2007, 3(10), 95-100.

21 OECD 2001-Guideline on Acute oral toxicity (AOT) Environmental health and safety monograph series on testing and adjustment number 425 .

22 A. Shirwaikar, K. Rajendran and R. Barik, Effect of aqueous bark extract of Garuga pinnata Roxb. in streptozotocinnicotinamide induced type-II diabetes mellitus, $J$. Ethnopharmacol., 2006, 107, 285-290.

23 L. Andersen, B. Dinesen, P. N. Jorgesen, F. Poulsen and M. F. Roder, Enzyme immuno assay for intact human insulin in serum or plasma, Clin. Chim. Acta, 1993, 38, 578-585.

24 A. Ramesh, N. N. Ratla and R. Indukur, Acute and sub-acute oral toxicity assessment of the cerium oxide nanoparticles in wistar rats, Int. J. Pharmacol., 2014, 5(1), 46-50.

25 A. Alkaladi and A. M. a. azem, Antidiabetic Activity of Zinc Oxide and Silver Nanoparticles on Streptozotocin-Induced Diabetic Rats, Int. J. Mol. Sci., 2014 Feb, 15(2), 2015-2023.

26 E. C. Chao, SGLT-2 Inhibitors: a new mechanism for glycemic control, Clin. Diabetes, 2014, 32(1), 4-11.

27 P. V. Roder, B. Wu, Y. Liu and W. Han, Pancreatic regulation of glucose homeostasis, Exp. Mol. Med., 2016, 48(3), 219.

28 K. Shanker, G. Mohan, M. Hussain, N. Jayarambabu and P. L. Pravallika, Green Biosynthesis, Characterization, In vitro Antidiabetic Activity, and Investigational Acute Toxicity Studies of Some Herbal-mediated Silver Nanoparticles on Animal Models, Pharmacogn. Mag., 2017, 13(49), 188-192.

29 A. Sengottaiyan and M. Govarthanan, Synthesis and characterization of Solanum nigrum-mediated silver nanoparticles and its protective effect on alloxan-induced diabetic rats, J. Nanostruct. Chem., 2016, 6(1), 41-48.

30 I. Ben-Slama, S. Amara, I. Mrad and N. Rihane, Sub-Acute Oral Toxicity of Zinc Oxide Nanoparticles in Male Rats, $J$. Nanomed. Nanotechnol., 2016, 6, 284. 